\title{
Effects of pomegranate and pomegranate-apple blend juices on the growth characteristics of Alicyclobacillus acidoterrestris DSM 3922 type strain vegetative cells and spores
}

\author{
Celenk Molva, Ayse Handan Baysal * \\ Department of Food Engineering, Izmir Institute of Technology, Urla 35437, Izmir, Turkey
}

\section{A R T I C L E I N F O}

\section{Article history:}

Received 23 September 2014

Received in revised form 5 January 2015

Accepted 27 January 2015

Available online 3 February 2015

Chemical compounds studied in this article:

Gallic acid (PubChem CID: 370)

Disodium carbonate (PubChem CID: 10340)

Sodium acetate trihydrate (PubChem CID:

23665405)

2,4,6-Tripyridyl-s-triazine (PubChem CID:

77258)

Ferric chloride (PubChem CID: 24380)

Trolox (PubChem CID: 40639)

2,2-Diphenyl-2-picrylhydrazyl (PubChem CID:

2735032)

Keywords:

Alicyclobacillus acidoterrestris

Inhibition

Juice

Spoilage

Sporulation media

\begin{abstract}
A B S T R A C T
The present study examined the growth characteristics of Alicyclobacillus acidoterrestris DSM 3922 vegetative cells and spores after inoculation into apple, pomegranate and pomegranate-apple blend juices $(10,20,40$ and $80 \%, \mathrm{v} / \mathrm{v}$ ). Also, the effect of sporulation medium was tested using mineral [Bacillus acidoterrestris agar (BATA) and Bacillus acidocaldarius agar (BAA)] and non-mineral containing media [potato dextrose agar (PDA) and malt extract agar (MEA)]. The juice samples were inoculated separately with approximately $10^{5} \mathrm{CFU} / \mathrm{mL}$ cells or spores from different sporulation media and then incubated at $37^{\circ} \mathrm{C}$ for $336 \mathrm{~h}$. The number of cells decreased significantly with increasing pomegranate juice concentration in the blend juices and storage time $(p<0.001)$. Based on the results, 3.17, 3.53, and $3.72 \mathrm{log}$ cell reductions were observed in $40 \%, 80 \%$ blend and pomegranate juices, respectively while the cell counts attained approximately $7.17 \log \mathrm{CFU} / \mathrm{mL}$ in apple juice after $336 \mathrm{~h}$. On the other hand, the cell growth was inhibited for a certain time, and then the numbers started to increase after 72 and $144 \mathrm{~h}$ in $10 \%$ and $20 \%$ blend juices, respectively. After $336 \mathrm{~h}$, total population among spores produced on PDA, BATA, BAA and MEA indicated 1.49, 1.65, 1.67, and 1.28 log reductions in pomegranate juice; and 1.51, $1.38,1.40$ and $1.16 \log$ reductions in $80 \%$ blend juice, respectively. The inhibitory effects of $10 \%, 20 \%$ and $40 \%$ blend juices varied depending on the sporulation media used. The results obtained in this study suggested that pomegranate and pomegranate-apple blend juices could inhibit the growth of A. acidoterrestris DSM 3922 vegetative cells and spores.
\end{abstract}

(c) 2015 Elsevier B.V. All rights reserved.

\section{Introduction}

Fruit juices are traditionally pasteurized for the inactivation of spoilage and pathogen organisms. After pasteurization, products are stored at refrigerated or ambient temperatures (Smit et al., 2011). However, thermal resistance studies indicated the ability of Alicyclobacillus acidoterrestris to survive pasteurization applied to fruit juices and acidic products. Due to acidophilic nature, their endospores can germinate and increase in products to cell counts high enough to produce taint compounds leading to spoilage (Gocmen et al., 2005; Orr et al., 2000; Pettipher et al., 1997; Vieira et al., 2002; Wisotzkey et al., 1992).

Taint compounds responsible for off-flavor are guaiacol, 2,6dibromophenol, and 2-methoxyphenol. Among these compounds, guaiacol is the major compound related to taint production (Witthuhn et al., 2012). It is formed from ferulic acid via vanillin and can be detected

\footnotetext{
* Corresponding author. Tel.: +90232 7506187; fax: +90232 7506196

E-mail address: handanbaysal@iyte.edu.tr (A.H. Baysal).
}

by smell in fruit juices at $2 \mathrm{ppb}$ (Bevilacqua et al., 2008; Chang and Kang, 2004). Detectable taint production in fruit juices is generally reported when the levels of $A$. acidoterrestris $\mathrm{CFU} / \mathrm{mL}$ reach about $10^{4}-10^{5} \mathrm{CFU} / \mathrm{mL}$ (Komitopoulou et al., 1999).

The growth characteristics of $A$. acidoterrestris strains depend on the juice type and the isolation source (Goto, 2007). Single strength juice is an ideal environment for spore germination and growth leading to spoilage under certain conditions (Walls and Chuyate, 2000). The growth has been detected in various spoiled commercial pasteurized fruit juices such as apple, orange, tomato, white grape, pear, and grapefruit but not observed in red grape juice, pineapple juice, Amazonian fruit Cupuaçu, salsa, and apple-cranberry blend juices (Silva and Gibbs, 2001; Splittstoesser et al., 1994; Tokuda, 2007; Wisse and Parish, 1998). The reason for growth and spoilage in specific juices is unclear, but these juices might contain different concentrations of guaiacol precursors or growth inhibitors (Walls and Chuyate, 2000). These inhibitory compounds might inhibit either spore germination or vegetative cell growth (Tokuda, 2007). 
Pomegranate (Punica granatum L.) is one of the important fruits grown in Turkey, Iran, USA, Middle East, Mediterranean and Arabic countries (Maskan, 2006). Pomegranate juice contains water, organic acids, sugars, pectin, tannins (punicalagin, ellagic acids and gallic acid), flavonoids (catechol, catechins, epigallocatechins) and anthocyanins (3-glucosides and 3,5-diglucosides of delphinidin, cyanidin, and pelargonidin) (Boggia et al., 2013; López-Rubira et al., 2005; Tanveer et al., 2014). Pomegranate juice has much more antioxidant activity than other fruit juices and beverages (Gil et al., 2000). Nowadays, interest in pomegranate juice and its products has increased significantly for health benefits and placed them in the first line of functional juice market (Vegara et al., 2013). Due to high acidity, astringency, bitterness and other factors found in some fruits and vegetables having high nutritional values, the production of processed products from these plants is limited. Therefore, blending of two or more fruit or vegetable juices for the production of ready-to-drink beverages may be used as alternative. Blending of fruit juices provides improved flavor, taste, and nutritive value, decreases the production cost and leads to new product development (Bhardwaj and Pandey, 2011).

In our previous work (Molva and Baysal, 2014), we found that the wet-heat resistance of $A$. acidoterrestris DSM 3922 spores varied depending on the sporulation medium used. Such variations need to be considered when evaluating the survival and inactivation of Alicyclobacillus spp. in fruit juices.

Therefore, the objective of this study was to determine the inhibitory effects of pomegranate juice and pomegranate-apple blend juices $(10,20,40$ and $80 \%, v / v)$ on the vegetative cells of $A$. acidoterrestris DSM 3922 and spores prepared from different sporulation media.

\section{Material and methods}

\subsection{Bacterial strain and preparation of spore suspensions}

A. acidoterrestris DSM 3922 type strain was kindly provided by Karl Poralla (Deutsche Sammlung von Mikroorganismen und Zellkulturen's collection, Braunschweig, Germany) and used as a test organism in this study. For sporulation, $100 \mu \mathrm{L}$ of $4 \mathrm{~h}$-grown culture at $43{ }^{\circ} \mathrm{C}$ in Bacillus acidoterrestris broth (BATB, Döhler, Germany) was spread onto B. acidoterrestris agar (BATA, Merck), Bacillus acidocaldarius agar (BAA) (Darland and Brock, 1971), potato dextrose agar (PDA, BD Difco) and malt extract agar (MEA, Oxoid). All inoculated plates were incubated at $43{ }^{\circ} \mathrm{C}$ for 10 days until $85-90 \%$ of cells sporulated as determined under phase-contrast microscope (Olympus CX31, Japan). Spore suspensions were prepared based on the protocol developed by other researchers (Murray et al., 2007) and stored at $-20{ }^{\circ} \mathrm{C}$ for further use.

\subsection{Juice samples}

Concentrated apple juice ( $70.3^{\circ} \mathrm{Brix}$ ) and pomegranate juice ( $65^{\circ} \mathrm{Brix}$ ) were kindly provided by ASYA Fruit Juice and Food Ind. Inc. (Isparta, Turkey) and reconstituted to 11.30 and $14.26^{\circ} \mathrm{Brix}$ as determined by a refractometer (Mettler Toledo, USA). For the preparation of blend juices, pomegranate juice was mixed with apple juice aseptically with the ratio of $80 \%, 40 \%, 20 \%$ and $10 \%$ (v/v). Diluted juice samples were tested for the presence of Alicyclobacillus spp. using membrane filtration method. Briefly, the membranes $(0.45 \mu \mathrm{m}$ pore size, Sartorius) that had been used to filter the reconstituted juice samples $(50 \mathrm{~mL})$ were transferred aseptically onto BATA. Then, the membranes on the plates were incubated at $43{ }^{\circ} \mathrm{C}$ for up to seven days (Molva and Baysal, 2014).

\subsection{Total phenol content}

The total phenol content (TPC) of the juice samples was determined according to Folin-Ciocalteu method as described previously (Al-Zoreky, 2009). A calibration curve was prepared using standard solutions of gallic acid $(0-0.09 \mathrm{mg} / \mathrm{mL})$ and the results were expressed in gallic acid equivalents (GAE) in $\mathrm{mg} / 100 \mathrm{~mL}$ juice.

\subsection{Antioxidant activity}

Ferric reducing antioxidant power (FRAP) and free radical scavenging activity of the juice samples were determined according to the method described previously (Bi et al., 2013). The results of FRAP assay were expressed as Trolox equivalents (TE) using a calibration curve in the range of $0-0.1 \mathrm{mM}$. Free radical scavenging activity was determined using a stable 2,2-diphenyl-2-picrylhydrazyl radical (DPPH) and calculated as \% inhibition of DPPH using the equation below (Katalinić et al., 2010).

$$
(\% \text { Inhibition of } \mathrm{DPPH})=\left[\left(\mathrm{OD}_{\text {control }}-\mathrm{OD}_{\text {sample }}\right) / \mathrm{OD}_{\text {control }}\right] \cdot 100 \text {. }
$$

\subsection{Inhibitory effect on A. acidoterrestris vegetative cells}

A. acidoterrestris cells were grown overnight on PDA at $43^{\circ} \mathrm{C}$. The colonies were suspended in $10 \mathrm{~mL}$ Maximum Recovery Diluent (MRD, Oxoid) to obtain a bacterial density of McFarland $1.0\left(10^{6} \mathrm{CFU} / \mathrm{mL}\right)$ by using a densitometer (Den-1, HVD Life Sciences, Austria). After centrifugation at $16,000 \times g$ for $5 \mathrm{~min}$, the pellet was suspended in $10 \mathrm{~mL}$ apple; pomegranate and pomegranate-apple blend juices [80\%, 40\%, 20\%, 10\% $(\mathrm{v} / \mathrm{v})]$. The initial cell population was determined for each juice sample. Next, the inoculated samples were incubated at $37{ }^{\circ} \mathrm{C}$ by shaking (Lab-Line MaxQ 4450 incubated shaker) at $120 \mathrm{rev} / \mathrm{min}$. At regular time intervals, the samples were serially diluted in MRD; 10fold dilutions were then spread onto the surface of PDA ( $\mathrm{pH} 3.5$ ). Finally, the plates were incubated at $43{ }^{\circ} \mathrm{C}$ for $48 \mathrm{~h}$.

\subsection{Inhibitory effect on A. acidoterrestris spores from different media}

Since there is no standardized medium for the production of A. acidoterrestris spores (Molva and Baysal, 2014), different media such as PDA, BATA, BAA, and MEA were used for sporulation. Before inoculation into juice samples, each spore suspension $\left(10^{6} \mathrm{CFU} / \mathrm{mL}\right)$ was heat shocked at $80^{\circ} \mathrm{C} / 10 \mathrm{~min}$ and cooled on ice. After centrifugation at $16,000 \times \mathrm{g}$ for $5 \mathrm{~min}$, the pellet was suspended in $10 \mathrm{~mL}$ apple; pomegranate and pomegranate-apple blend juices [80\%, 40\%, 20\%, $10 \%(\mathrm{v} / \mathrm{v})]$. Then, the initial spore population was determined. After that, the inoculated samples were incubated at $37^{\circ} \mathrm{C}$ by shaking (Lab-Line MaxQ 4450 incubated shaker) at $120 \mathrm{rev} / \mathrm{min}$. The total population (cells and spores) was evaluated at regular time intervals without heat shock treatments. The samples were serially diluted in MRD; then 10-fold dilutions were spread onto the surface of PDA ( $\mathrm{pH} 3.5$ ). Inoculated plates were incubated at $43^{\circ} \mathrm{C}$ for $48 \mathrm{~h}$.

\subsection{Statistical analysis}

Each experiment was performed in triplicate. The mean values and standard deviations were calculated by Excel (Microsoft Corp., USA). Data from three replicates were analyzed by one way analysis of variance (ANOVA) using Minitab 16.0 (Minitab Inc., UK). The TukeyKramer test was used to compare the means of treated groups. The confidence interval used to determine statistical significance was set at $95 \%$ $(p<0.05)$.

\section{Results and discussion}

\subsection{Juice samples}

The $\mathrm{pH}$, ${ }^{\circ}$ Brix, TPC, FRAP and DPPH-radical scavenging activities of juice samples used in this study are presented in Table 1. 
Table 1

$\mathrm{pH},{ }^{\circ} \mathrm{Brix}, \mathrm{TPC}, \mathrm{FRAP}$ and DPPH-radical scavenging activities of juice samples.

\begin{tabular}{|c|c|c|c|c|c|}
\hline Juice $^{a}$ & $\mathrm{pH}$ & ${ }^{\circ}$ Brix & $\begin{array}{l}\mathrm{TPC} \\
\mathrm{mg} \mathrm{GAE} / 100 \mathrm{~mL}\end{array}$ & $\begin{array}{l}\text { FRAP } \\
\text { mmole TE/L }\end{array}$ & $\%$ inhibition of DPPH \\
\hline $\mathrm{PJ}$ & $3.36(0.00)^{\mathrm{A}}$ & $14.26(0.02)^{\mathrm{A}}$ & $400.48 \pm 9.41^{\mathrm{A}}$ & $40.05 \pm 1.05^{\mathrm{A}}$ & $80.41 \pm 0.06^{\mathrm{B}}$ \\
\hline $80 \% \mathrm{BJ}$ & $3.42(0.00)^{\mathrm{B}}$ & $13.66(0.05)^{\mathrm{B}}$ & $243.23 \pm 3.40^{\mathrm{B}}$ & $35.31 \pm 1.93^{\mathrm{B}}$ & $83.81 \pm 0.94^{\mathrm{B}}$ \\
\hline $40 \% \mathrm{BJ}$ & $3.60(0.00)^{C}$ & $12.55(0.01)^{C}$ & $157.78 \pm 5.23^{C}$ & $16.85 \pm 1.15^{\mathrm{C}}$ & $88.79 \pm 1.91^{\mathrm{A}}$ \\
\hline $20 \% \mathrm{BJ}$ & $3.74(0.00)^{\mathrm{D}}$ & $12.00(0.03)^{\mathrm{D}}$ & $89.41 \pm 2.54^{\mathrm{D}}$ & $8.21 \pm 0.63^{\mathrm{D}}$ & $89.74 \pm 1.55^{\mathrm{A}}$ \\
\hline $10 \% \mathrm{BJ}$ & $3.82(0.01)^{\mathrm{E}}$ & $11.63(0.01)^{\mathrm{E}}$ & $67.21 \pm 1.47^{\mathrm{E}}$ & $4.65 \pm 0.07^{\mathrm{E}}$ & $83.91 \pm 0.94^{\mathrm{B}}$ \\
\hline AJ & $3.96(0.00)^{\mathrm{F}}$ & $11.30(0.10)^{\mathrm{F}}$ & $26.48 \pm 1.13^{\mathrm{F}}$ & $0.93 \pm 0.03^{\mathrm{F}}$ & $19.01 \pm 1.16^{\mathrm{C}}$ \\
\hline
\end{tabular}

All data were the means \pm standard deviation from three experiments $(n=3)$. Values with different capital letters in the same column are significantly different $(p<0.05)$.

a PJ: pomegranate juice; BJ: blend juice; AJ: apple juice.

\subsubsection{Total phenol content}

Phenolic content of the compounds are important for their antimicrobial activity. Total phenol content of the apple juice was found to be $26.48 \pm 1.13 \mathrm{mg} \mathrm{GAE} / 100 \mathrm{~mL}$ juice (Table 1 ) and this finding was in good agreement with previously published data (Caminiti et al., 2012). Also, TPC of the pomegranate juice was $400.48 \pm 9.41 \mathrm{mg} \mathrm{GAE} / 100 \mathrm{~mL}$ juice (Table 1 ) which was quite high compared to the literature from the commercial juices in Turkey (Tezcan et al., 2009). Similar to apple juice, the differences between TPC are related to the fruit processing method. Especially, some extraction methods can involve rubbing the internal part of the rind, and may cause the extraction of the phenolic contents (Vázquez-Araújo et al., 2011). Also, the TPC of the blend juices ranged from 67.21 to $243.23 \mathrm{mg} \mathrm{GAE} / 100 \mathrm{~mL}$ juice (Table 1 ). There was a strong correlation between the TPC and the concentration of pomegranate juice in the blend juice samples $\left(R^{2}>0.956\right)$.

\subsubsection{Antioxidant activity}

Pomegranate juice displayed higher antioxidant capacity (40.05 mM TE) than apple juice (0.93 mM TE) according to FRAP method (Table 1) since commercial pomegranate juice obtained by pressing this fruit contains water soluble punicalagin which is a potent antioxidant in significant amounts (Patel et al., 2008). The FRAP values of blend juices were strongly correlated with the concentration of pomegranate juice in the apple juice $\left(R^{2}>0.993\right)$ and ranged from 4.65 to $35.31 \mathrm{mM}$ TE (Table 1 ). Based on the DPPH method, the apple and pomegranate juices were found to exhibit $19.01 \%$ and $80.41 \%$ inhibition, respectively (Table 1 ). And, \% inhibition of pomegranate juice, $80 \%$ and $10 \%$ blend juices were not statistically different $(p>0.05)$. In addition, $20 \%$ and $40 \%$ blend juices yielded the highest inhibition with $89.74 \%$ and $88.79 \%$, respectively.

\subsection{Inhibitory effect on A. acidoterrestris vegetative cells}

The average initial cell population was about 5.43, 5.49, 5.53, 5.55, 5.44 and $5.62 \log$ CFU/mL for $10 \%, 20 \%, 40 \%, 80 \%$ blend, apple and pomegranate juices, respectively (Table 2). The $\mathrm{pH}(3.36-3.96)$ and ${ }^{\circ}$ Brix values (11.30-14.26) of juice samples (Table 1 ) do not appear to be limiting on A. acidoterrestris DSM 3922, since its survival and growth at these values have been demonstrated (Tokuda, 2007). While A. acidoterrestris cells reached $7.27 \mathrm{log} \mathrm{CFU} / \mathrm{mL}$ within $24 \mathrm{~h}$ incubation in the apple juice, the number of cells decreased significantly with increasing pomegranate juice concentration in the blend juices and storage time $(p<0.001)$. After 336 h, 3.17, 3.53 and $3.72 \log \mathrm{CFU} / \mathrm{mL}$ reductions were observed in $40 \%, 80 \%$ blend juices and pomegranate juice, respectively (Table 2). On the other hand, the growth was inhibited for a certain time in $10 \%$ and $20 \%$ blend juices, and then the cell numbers started to increase after 72 and $144 \mathrm{~h}$ storage, respectively. The population attained approximately $7.17 \log \mathrm{CFU} / \mathrm{mL}$ in apple juice at the end of the incubation while the cell numbers reached 7.12 and $7.00 \log \mathrm{CFU} / \mathrm{mL}$ in $10 \%$ and $20 \%$ blend juices, respectively (Table 2 ).

The antimicrobial activity of pomegranate juice was reported to be due to tannins such as ellagitannins and other high molecular weight tannins (Al-Zoreky, 2009; Machado et al., 2003; Türkyılmaz et al., 2013). More specifically, tannins in pomegranate juice could exhibit antimicrobial activity in different mechanisms. First, they might form complexes with proteins found in cell walls decreasing both cell permeability and substrate transportation into the cells. Secondly, they might inhibit essential bacterial enzymes. Also, they might form stable complexes with metal ions such as $\mathrm{Fe}^{2+}$ and $\mathrm{Cu}^{2+}$. Therefore, they decrease the availability of these ions for bacteria and affect the activity of metalloenzymes (Puupponen-Pimiä et al., 2005). In a recent study (Türkyılmaz et al., 2013), antimicrobial activity of pomegranate juice was tested against Gram-positive (Bacillus megaterium, Bacillus subtilis, Staphylococcus aureus, Lactobacillus plantarum) and Gram-negative bacteria (Pseudomonas spp., Escherichia coli, E. coli 0157:H7, Salmonella Enteritidis, Enterobacter cloacae, and Citrobacter freundii) and molds (Aspergillus niger, Aspergillus spp., Penicillum spp.). They found that pomegranate juice showed higher antimicrobial activity on Gram-positive than Gram-negative bacteria.

Structural deformations such as leakage of cellular constituents; perforations and blebs on the cell surface during growth in 40\%, 80\% pomegranate-apple blend and pomegranate juices were observed by scanning electron microscopy (SEM) at the end of the incubation period (data not shown). Since pomegranate juice has higher TPC than apple juice, the antimicrobial mechanism of the pomegranate juice on the cell structure is very likely to have been caused by the action of phenolics as observed in previously published data (Molva and Baysal, 2015).

Table 2

Counts of vegetative cells $(\log \mathrm{CFU} / \mathrm{mL})$ in the juice samples during storage at $37^{\circ} \mathrm{C}$.

\begin{tabular}{|c|c|c|c|c|c|c|}
\hline Storage (h) & $\mathrm{PJ}$ & $80 \%$ BJ & $40 \% \mathrm{BJ}$ & $20 \% \mathrm{BJ}$ & $10 \% \mathrm{BJ}$ & $\mathrm{AJ}^{\mathrm{a}}$ \\
\hline 0 & $5.62(0.09)^{\mathrm{Aa}}$ & $5.55(0.07)^{\mathrm{Aa}}$ & $5.53(0.00)^{\mathrm{Aa}}$ & $5.49(0.05)^{\mathrm{Da}}$ & $5.43(0.18)^{\mathrm{Ca}}$ & $5.44(0.06)^{\mathrm{Ba}}$ \\
\hline 24 & $4.42(0.19)^{\mathrm{Bb}}$ & $4.19(0.03)^{\mathrm{Bb}}$ & $4.51(0.12)^{\mathrm{Bb}}$ & $4.29(0.05)^{\mathrm{Eb}}$ & $4.53(0.09)^{\mathrm{Db}}$ & $7.27(0.67)^{\mathrm{Aa}}$ \\
\hline 48 & $4.02(0.04)^{\mathrm{Cd}}$ & $3.89(0.04)^{\mathrm{Ce}}$ & $4.01(0.01)^{\mathrm{Cd}}$ & $4.15(0.03)^{\mathrm{Ec}}$ & $4.78(0.01)^{\mathrm{Db}}$ & $7.30(0.00)^{\mathrm{Aa}}$ \\
\hline 72 & $3.87(0.21)^{\mathrm{Cb}}$ & $3.72(0.01)^{\mathrm{Db}}$ & $3.92(0.04)^{\mathrm{Cb}}$ & $4.09(0.18)^{\mathrm{Eb}}$ & $7.78(0.07)^{\mathrm{Aa}}$ & $7.59(0.12)^{\mathrm{Aa}}$ \\
\hline 144 & $3.07(0.10)^{\mathrm{Dc}}$ & $2.99(0.08)^{\mathrm{Ec}}$ & $3.12(0.00)^{\mathrm{Dc}}$ & $6.59(0.08)^{\mathrm{Cb}}$ & $6.84(0.16)^{\mathrm{Bb}}$ & $7.17(0.08)^{\mathrm{Aa}}$ \\
\hline 168 & $2.93(0.00)^{\mathrm{DEb}}$ & $2.91(0.00)^{\mathrm{Eb}}$ & $2.95(0.04)^{\mathrm{Eb}}$ & $7.56(0.08)^{\mathrm{Aa}}$ & $7.67(0.13)^{\mathrm{Aa}}$ & $7.54(0.13)^{\mathrm{Aa}}$ \\
\hline 240 & $2.67(0.13)^{\mathrm{Eb}}$ & $2.71(0.02)^{\mathrm{Fb}}$ & $2.69(0.00)^{\mathrm{Fb}}$ & $7.14(0.09)^{\mathrm{Ba}}$ & $6.87(0.04)^{\mathrm{Ba}}$ & $6.95(0.24)^{\mathrm{Aa}}$ \\
\hline 336 & $1.90(0.08)^{\mathrm{Fc}}$ & $2.02(0.09)^{\mathrm{Gbc}}$ & $2.36(0.01)^{\mathrm{Gb}}$ & $7.00(0.16)^{\mathrm{Ba}}$ & $7.12(0.06)^{\mathrm{Ba}}$ & $7.17(0.19)^{\mathrm{Aa}}$ \\
\hline
\end{tabular}

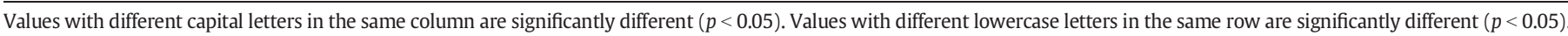

a The experiments were repeated three times, and data are expressed as mean \pm standard deviation. 


\subsection{Inhibitory effect on A. acidoterrestris spores from different media}

Spores prepared from BATA and BAA media did not germinate and were only slightly inactivated during incubation in pomegranate juice and blend juices. The spores produced on BATA were inoculated into pomegranate juice, $80 \%, 40 \%, 20 \%$ and $10 \%$ blend juices at initial levels of 5.65, 5.54, 5.43, 5.38 and $5.31 \log \mathrm{CFU} / \mathrm{mL}$ and the levels were 3.99, $4.16,4.20,4.15$, and $4.30 \log \mathrm{CFU} / \mathrm{mL}$, respectively at the end of the incubation. For spores produced on BAA, the initial levels were 5.48, 5.31, 5.42, 5.36 and $5.15 \log \mathrm{CFU} / \mathrm{mL}$ in pomegranate juice, $80 \%, 40 \%, 20 \%$ and $10 \%$ blend juices and the levels were $3.81,3.91,4.12,4.33$ and $4.41 \log \mathrm{CFU} / \mathrm{mL}$, respectively after $336 \mathrm{~h}$ (Fig. 1). However, in apple juice only, both spores germinated after $24 \mathrm{~h}$ leading to an increase to approximately $10^{7} \mathrm{CFU} / \mathrm{mL}$ by the end of incubation. On the other hand, the germination and inactivation of spores prepared on PDA and MEA differed depending on the type of juice sample analyzed. Similarly, spores prepared from MEA did not germinate and were slightly inactivated during incubation in pomegranate juice and blend juices ranging from $20 \%$ to $80 \%$. The initial levels of spores from MEA were 5.38, 5.32, 5.40, and $5.45 \log \mathrm{CFU} / \mathrm{mL}$ in pomegranate juice, $80 \%, 40 \%$, and $20 \%$ blend juices and the levels were 4.10, 4.16, 4.20, and $4.78 \log \mathrm{CFU} / \mathrm{mL}$, respectively after $336 \mathrm{~h}$ (Fig. 1). However, in $10 \%$ blend juice and apple juice, spores from MEA media germinated after $96 \mathrm{~h}$ and $24 \mathrm{~h}$, respectively leading to an increase to approximately $10^{7} \mathrm{CFU} / \mathrm{mL}$ by the end of incubation. Spores obtained from PDA did not germinate and were inactivated during incubation in pomegranate juice and $80 \%$ blend juice. The inoculum levels were 5.59 and $5.55 \log \mathrm{CFU} / \mathrm{mL}$ in pomegranate and $80 \%$ blend juices, respectively. After $336 \mathrm{~h}$, the levels were 4.10 and $4.04 \log$ CFU/mL, respectively. However, the germination of spores was observed in $40 \%, 20 \%$, and $10 \%$ blend juices and apple juice after $240 \mathrm{~h}, 96 \mathrm{~h}, 48 \mathrm{~h}$ and $24 \mathrm{~h}$, respectively attaining to approximately $10^{7} \mathrm{CFU} / \mathrm{mL}$ after $336 \mathrm{~h}$.

The presence of certain transition metals in the sporulation media is important for spore properties such as spore formation, heat resistance and dormancy (Kihm et al., 1988). It has been well documented that stabilization of Ca-DPA and the ability to strongly bind divalent cations contribute to the heat resistance (Yamazaki et al., 1997). In another study, heat resistances of A. acidoterrestris DSM 3922 spores obtained from mineral containing media (BATA and BAA) were found to be
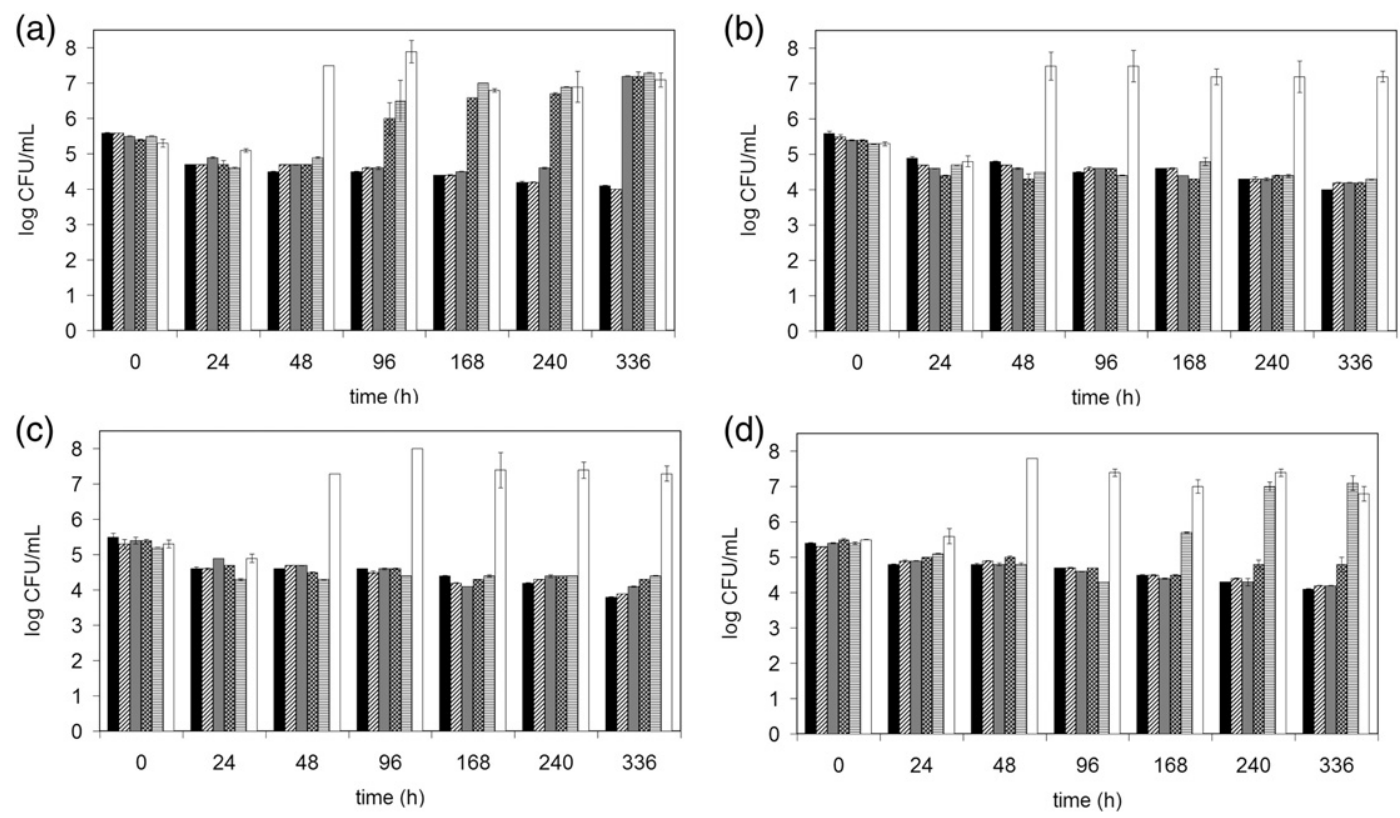

-PJ $\mathbb{R} 80 \%$ BJ $\square 40 \%$ BJ $\approx 20 \%$ BJ 自 $10 \%$ BJ $\square$ AJ

higher than those of spores from non-mineral containing media (PDA and MEA) (Molva and Baysal, 2014). However, very limited data is available on the sporulation medium dependency of antimicrobial activity. It was only reported that the antimicrobial activity of grape seed extract in the apple juice against spores was variable depending on the concentration tested and type of sporulation medium used (Molva and Baysal, 2015). In accordance with the results of this study, the spores produced on mineral containing media (BATA and BAA) were found to be sensitive to all tested concentrations of grape seed extract. Finally, we suggest that the presence or absence of certain metal ions in the sporulation medium might be important for the antimicrobial activity of phenolic compounds against spores due to the interactions between tannins in pomegranate juice and metal ions $\left(\mathrm{Fe}^{2+}\right.$ and $\mathrm{Cu}^{2+}$ ) by forming stable complexes and thereby decreasing the availability of these ions (Puupponen-Pimiä et al., 2005).

The spores from PDA and BATA were also examined by SEM to visualize the spore morphology that occurred during growth in apple juice and pomegranate juice after $336 \mathrm{~h}$ (data not presented). Similar to our previous findings (Molva and Baysal, 2015), both vegetative cells and spores were present during growth in apple juice but no vegetative cells were formed during growth in pomegranate juice possibly due to the action of certain compounds inhibiting spore germination/ outgrowth. In the related literature, the growth inhibition of A. acidoterrestris spores in red grape juice has also been reported (Splittstoesser et al., 1994). This inhibitory effect was found to be not only due to the synergistic effects of polyphenols. Also, phenolic compounds in red grape juice showed stronger antimicrobial activity at lower $\mathrm{pH}$ values, lower activity in the presence of fibers and no activity at the higher $\mathrm{pH}$ values (Tokuda, 2007).

\section{Conclusions}

Under the light of the results of this study, it may be concluded that the blending of pomegranate and apple juices can inhibit the growth of A. acidoterrestris cells and spore germination/outgrowth. On the other hand, further research should be evaluated to fully understand the antimicrobial mode of activity of pomegranate juice or its components on A. acidoterrestris spores.

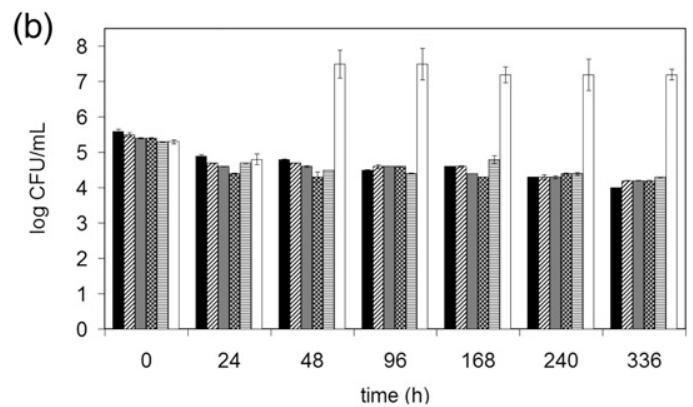

nate-apple blend juices during $336 \mathrm{~h}$ of storage as affected by sporulation medium used to Fig. 1. Survival and germination of A. acidoterrestris spores in p
prepare the spores. PDA (a), BATA (b), BAA (c), and MEA (d). 


\section{Acknowledgments}

The authors thank the members of the Center for Materials Research (IZTECH MAM) of Izmir Institute of Technology for SEM imaging.

\section{References}

Al-Zoreky, N.S., 2009. Antimicrobial activity of pomegranate (Punica granatum L.) fruit peels. Int. J. Food Microbiol. 134, 244-248.

Bevilacqua, A., Sinigaglia, M., Corbo, M.R., 2008. Alicyclobacillus acidoterrestris: new methods for inhibiting spore germination. Int. J. Food Microbiol. 125, 103-110.

Bhardwaj, R.L., Pandey, S., 2011. Juice blends-a way of utilization of under-utilized fruits, vegetables, and spices: a review. Crit. Rev. Food Sci. Nutr. 51, 563-570.

Bi, X., Liu, F., Rao, L., Li, J., Liu, B., Liao, X., Wu, J., 2013. Effects of electric field strength and pulse rise time on physicochemical and sensory properties of apple juice by pulsed electric field. Innov. Food Sci. Emerg. Technol. 17, 85-92.

Boggia, R., Casolino, M.C., Hysenaj, V., Oliveri, P., Zunin, P., 2013. A screening method based on UV-visible spectroscopy and multivariate analysis to assess addition of filler juices and water to pomegranate juices. Food Chem. 140, 735-741.

Caminiti, I.M., Palgan, I., Muñoz, A., Noci, F., Whyte, P., Morgan, D.J., Cronin, D.A., Lyng, J.G., 2012. The effect of ultraviolet light on microbial inactivation and quality attributes of apple juice. Food Bioprocess Technol. 5, 680-686.

Chang, S.S., Kang, D.H., 2004. Alicyclobacillus spp. in the fruit juice industry: history, characteristics, and current isolation/detection procedures. Crit Rev. Microbiol. 30, 55-74.

Darland, G., Brock, T.D., 1971. Bacillus acidocaldarius sp. nov., an acidophilic thermophilic spore-forming bacterium. J. Gen. Microbiol. 67, 9-15.

Gil, M.I., Tomas-Barberan, F.A., Hess-Pierce, B., Holcroft, D.M., Kader, A.A., 2000. Antioxidant activity of pomegranate juice and its relationship with phenolic composition and processing. J. Agric. Food Chem. 48, 4581-4589.

Gocmen, D., Elston, A., Williams, T., Parish, M., Rouseff, R.L., 2005. Identification of medicinal off-flavours generated by Alicyclobacillus species in orange juice using GColfactometry and GC-MS. Lett. Appl. Microbiol. 40, 172-177.

Goto, K., 2007. Parameters for detection of Alicyclobacillus and test methods. In: Yokota, A., Fujii, T., Goto, K. (Eds.), Alicyclobacillus. Springer, Japan, pp. 49-78.

Katalinić, V., Možina, S.S., Skroza, D., Generalić, I., Abramovič, H., Miloš, M., Ljubenkov, I, Piskernik, S., Pezo, I., Terpinc, P., Boban, M., 2010. Polyphenolic profile, antioxidant properties and antimicrobial activity of grape skin extracts of 14 Vitis vinifera varieties grown in Dalmatia (Croatia). Food Chem. 119, 715-723.

Kihm, D., Hutton, M., Hanlin, J., Johnson, E., 1988. Zinc stimulates sporulation in Clostridium botulinum 113B. Curr. Microbiol. 17, 193-198.

Komitopoulou, E., Boziaris, I.S., Davies, E.A., Delves-Broughton, J., Adams, M.R., 1999. Alicyclobacillus acidoterrestris in fruit juices and its control by nisin. Int. J. Food Sci. Technol. 34, 81-85.

López-Rubira, V., Conesa, A., Allende, A., Artés, F., 2005. Shelf life and overall quality of minimally processed pomegranate arils modified atmosphere packaged and treated with UV-C. Postharvest Biol. Technol. 37, 174-185.

Machado, T.B., Pinto, A.V., Pinto, M.C.F.R., Leal, I.C.R., Silva, M.G., Amaral, A.C.F., Kuster, R.M., Netto-dosSantos, K.R., 2003. In vitro activity of Brazilian medicinal plants, naturally occurring naphthoquinones and their analogues, against methicillinresistant Staphylococcus aureus. Int. J. Antimicrob. Agents 21, 279-284.

Maskan, M., 2006. Production of pomegranate (Punica granatum L.) juice concentrate by various heating methods: colour degradation and kinetics. J. Food Eng 72, 218-224.

Molva, C., Baysal, A.H., 2014. Effect of sporulation medium on wet-heat resistance and structure of Alicyclobacillus acidoterrestris DSM 3922-type strain spores and modeling of the inactivation kinetics in apple juice. Int. J. Food Microbiol. 189, 82-88.

Molva, C., Baysal, A.H., 2015. Antimicrobial activity of grape seed extract on Alicyclobacillus acidoterrestris DSM 3922 vegetative cells and spores in apple juice. LWT Food Sci. Technol. 60, 238-245.
Murray, M.B., Gurtler, J.B., Ryu, J.H., Harrison, M.A., Beuchat, L.R., 2007. Evaluation of direc plating methods to enumerate Alicyclobacillus in beverages. Int. J. Food Microbiol. 115, 59-69.

Orr, R.V., Shewfelt, R.L., Huang, C.J., Tefera, S., Beuchat, L.R., 2000. Detection of guaiacol produced by Alicyclobacillus acidoterrestris in apple juice by sensory and chromatographic analyses, and comparison with spore and vegetative cell populations. J. Food Prot. 63, 1517-1522.

Patel, C., Dadhaniya, P., Hingorani, L., Soni, M.G., 2008. Safety assessment of pomegranate fruit extract: acute and subchronic toxicity studies. Food Chem. Toxicol. 46, 2728-2735.

Pettipher, G.L., Osmundson, M.E., Murphy, J.M., 1997. Methods for the detection and enumeration of Alicyclobacillus acidoterrestris and investigation of growth and production of taint in fruit juice and fruit juice-containing drinks. Lett. Appl. Microbiol. 24, 185-189.

Puupponen-Pimiä, R., Nohynek, L., Hartmann-Schmidlin, S., Kähkönen, M., Heinonen, M. Määttä-Riihinen, K., Oksman-Caldentey, K.M., 2005. Berry phenolics selectively inhibit the growth of intestinal pathogens. J. Appl. Microbiol. 98, 991-1000.

Silva, F.V.M., Gibbs, P., 2001. Alicyclobacillus acidoterrestris spores in fruit products and design of pasteurization processes. Trends Food Sci. Technol. 12, 68-74

Smit, Y., Cameron, M., Venter, P., Witthuhn, R.C., 2011. Alicyclobacillus spoilage and isolation - a review. Food Microbiol. 28, 331-349.

Splittstoesser, D.F., Churey, J.J., Lee, C.Y., 1994. Growth characteristics of aciduric sporeforming bacilli isolated from fruit juices. J. Food Prot. 57, 1080-1083.

Tanveer, A., Farooq, U., Akram, K., Hayat, Z., Shafi, A., Nazar, H., Ahmad, Z., 2014 Pomegranate extracts: a natural preventive measure against spoilage and pathogenic microorganisms. Food Rev. Int. 31, 29-51.

Tezcan, F., Gültekin-Özgüven, M., Diken, T., Özçelik, B., Erim, F.B., 2009. Antioxidant activity and total phenolic, organic acid and sugar content in commercial pomegranate juices. Food Chem. 115, 873-877.

Tokuda, H., 2007. Growth profile of Alicyclobacillus in fruit juices. In: Yokota, A., Fujii, T., Goto, K. (Eds.), Alicyclobacillus. Springer, Japan, pp. 92-105.

Türkyılmaz, M., Tağı, Ş., Dereli, U., Özkan, M., 2013. Effects of various pressing programs and yields on the antioxidant activity, antimicrobial activity, phenolic content and colour of pomegranate juices. Food Chem. 138, 1810-1818.

Vázquez-Araújo, L., Chambers, E., Adhikari, K., Carbonell-Barrachina, A.A., 2011. Physicochemical and sensory properties of pomegranate juices with pomegranate albedo and carpellar membranes homogenate. LWT Food Sci. Technol. 44, 2119-2125.

Vegara, S., Martí, N., Mena, P., Saura, D., Valero, M., 2013. Effect of pasteurization process and storage on color and shelf-life of pomegranate juices. LWT Food Sci. Technol. 54 592-596.

Vieira, M.C., Teixeira, A.A., Silva, F.M., Gaspar, N., Silva, C.L.M., 2002. Alicyclobacillus acidoterrestris spores as a target for Cupuaçu (Theobroma grandiflorum) nectar thermal processing: kinetic parameters and experimental methods. Int. J. Food Microbiol. 77, 71-81.

Walls, I., Chuyate, R., 2000. Spoilage of fruit juices by Alicyclobacillus acidoterrestris. Food Aust. 52, 286-288

Wisotzkey, J.D., Jurtshuk Jr., P., Fox, G.E., Deinhard, G., Poralla, K., 1992. Comparative sequence analyses on the 16S rRNA (rDNA) of Bacillus acidocaldarius, Bacillus acidoterrestris, and Bacillus cycloheptanicus and proposal for creation of a new genus, Alicyclobacillus gen. nov. Int. J. Syst. Bacteriol. 42, 263-269.

Wisse, C.A., Parish, M.E. 1998. Isolation and enumeration of sporeforming thermoacidophilic, rod-shaped bacteria from citrus processing environments. Dairy Food Environ. Sanit. 18, 504-509.

Witthuhn, R.C., van der Merwe, E., Venter, P., Cameron, M., 2012. Guaiacol production from ferulic acid, vanillin and vanillic acid by Alicyclobacillus acidoterrestris. Int. J. Food Microbiol. 157, 113-117.

Yamazaki, K., Kawai, Y., Inoue, N., Shinano, H., 1997. Influence of sporulation medium and divalent ions on the heat resistance of Alicyclobacillus acidoterrestris spores. Lett. Appl. Microbiol. 25, 153-156. 